Dossiê - Para além do “ativismo judicial” e da “judicialização da política” DOI: $10.5433 / 2176-6665.2016 \mathrm{v} 21 \mathrm{~N} 1 \mathrm{P} 124$

\title{
CONFLITOS FUNDiÁRIOS URBANOS E SISTEMA DE JUSTIÇA: JUdicializaÇÃo da POLÍtica OU POLITIZAÇÃo dA JUSTIÇA?
}

\author{
Alessandra Teixeira ${ }^{1}$ e Eliane Alves da Silva ${ }^{2}$
}

\begin{abstract}
Resumo
Este artigo pretende problematizar o papel do sistema de justiça em conflitos fundiários urbanos, tomando como base de análise experiências de remoção realizadas no município de São Paulo. Para além da oposição posse vs. propriedade, declarada quando da exigência constitucional da função social da propriedade e já bastante explorada pela bibliografia, o texto traz um elemento adicional para o debate, explorando o papel, o alcance e os limites do sistema de justiça em conflitos fundiários que opõem direito à moradia e direito ambiental. Considerando a presença ainda incipiente de discussão da judicialização no campo da política urbana, sendo esta mais frequente no âmbito das políticas de saúde e educação, o texto pretende oferecer uma contribuição ao debate.
\end{abstract}

Palavras-chave: Política urbana. Judicialização. Habitação popular. Defensoria Pública.

\section{URBAN LAND CONFLICTS AND JUDICIAL SYSTEM: JUDICIALIZATION OF POLITICS OR POLITICIZATION OF JUSTICE?}

\begin{abstract}
This article proposes to discuss the role of judicial system in land urban conflicts. In order to do that the article analyses some experiences of forced evictions occurred in the city of São Paulo. Beyond the opposition of property and land tenure, declared with the constitutional principle of social function of property, and much

1 Professora-adjunta de Políticas Públicas na Universidade Federal do ABC (UFABC), Brasil. alessandra.teixeira@ufabc.edu.br

2 Doutora em Sociologia pela Universidade de São Paulo (USP), Brasil. elianeas@usp.br
\end{abstract}


explored by the bibliography, this text brings an additional element to the debate exploring the role, the advances and the limits of the presence of judicial system in land conflicts that oppose housing rights and environmental law. Considering the incipient presence of the discussion of judicialization in the domain of urban policy compared to the discussion in policies of health and education, this text intends offer a contribution to enlarge this debate.

Keywords: Urban policy. Judicialization. Poor housing. Public Defender.

\section{INTRODUÇÃo}

$\mathrm{E}$ ste artigo pretende problematizar o papel do sistema de justiça em conflitos fundiários urbanos, levando em conta as dicotomias que têm acompanhado o debate sobre a chamada "judicialização da política" e, mais especificamente, sobre a atuação dos tribunais em uma área que historicamente foi marcada pela primazia do direito à propriedade.

Nessa longínqua trajetória das iniquidades no direito à moradia no país, marcada pela concentração fundiária como corolário da concentração de renda, pelo processo de urbanização irregular das cidades, cuja expressão sempre foi a precariedade habitacional das populações de baixa renda (dos cortiços e favelas às autoconstruções em áreas ocupadas nas periferias, não raro áreas de risco), é certo que a Constituição Federal de 1988 é um marco, ao menos normativo, de uma anunciada inflexão. O texto constitucional promoveu, pela primeira vez em nossa experiência, um tensionamento das categorias jurídicas até então orbitadas ao redor da primazia da propriedade civil, bem como estabilizadas e unificadas graças à prevalência do direito civil no ordenamento jurídico e de seu espectro liberal.

Com esse novo tensionamento irrompem as principais dicotomias com as quais se defronta hoje o debate sobre conflitos fundiários urbanos: direito individual $\mathrm{x}$ direito social, direito de propriedade $x$ direito de moradia/função social da propriedade, direito 
privado $\mathrm{x}$ direito público, direito civil $\mathrm{x}$ direito constitucional, direito social $\mathrm{x}$ direito difuso, substancialismo $\mathrm{x}$ procedimentalismo etc.

É certo que esse tensionamento é decorrente do fenômeno normativo de constitucionalização dos direitos econômicos e sociais, que ganhou impulso a partir da Segunda Guerra Mundial em grande parte dos sistemas jurídicos mundo a fora, alcançando as terras pátrias apenas com a redemocratização, já nos anos 80 . Referido fenômeno tem levado a uma maior juridificação ${ }^{3}$ das relações sociais, e a um protagonismo do sistema de justiça no processo de efetivação desses direitos (TEUBNER, 1986). Tal protagonismo, que recebe também a designação de "ativismo judicial", divide posições entre críticos severos e entusiastas, balizados, grosso modo, pelas perspectivas antagônicas procedimentalista e substancialista, respectivamente.

A intenção deste artigo não é adentrar tal debate, que vem, aliás, se sofisticando ao longo dos anos, através de pesquisas e dados empíricos que contribuem para melhor qualificar a discussão e superar seu embate puramente retórico (FERRAZ; VIEIRA, 2009; FANTI, 2009; OLIVEIRA; NORONHA, 2011; WANG, 2009). O que é importante reter dessa discussão, para os fins do presente artigo, é justamente aquilo que baliza sua polêmica: quais os limites e critérios para a adjudicação de direitos (individuais, coletivos e sociais) pela via judicial, numa democracia participativa? Até que ponto essa adjudicação pode violar - ou em sentido contrário, reforçar - o princípio da equidade, que se encontra no coração da Constituição de um Estado social?

Orientados por tal questão, Ferraz e Vieira (2009) empreenderam levantamento empírico sobre os impactos, no

3 O sociólogo do direito Gunther Teubner foi um dos primeiros autores a tratar do termo juridificação como um fenômeno do direito contemporâneo decorrente do welfare state, que implicaria na crescente judicialização das relações sociais frente o avanço do poder regulatório do direito positivo na vida social. Este mesmo autor distingue a juridificação da judicialização da política, desdobramento da primeira, expressa na efetiva utilização do sistema jurídico para realizar finalidades políticas (TEUBNER, 1986). No Brasil, o trabalho de Vianna, Carvalho e Melo (1999) seguiu perspectiva semelhante. 
orçamento público da saúde, das decisões da Justiça brasileira em litígios individuais que postulam direito a tratamento e/ou medicamentos não cobertos pela política nacional denominada SUS (Sistema Único de Saúde). A conclusão dos autores é a de que a Justiça brasileira opera uma verdadeira subversão dos princípios da equidade e da universalidade consagradores do SUS pela CF de 1988. Isso porque o sistema de justiça acaba por promover o acesso privilegiado à saúde àqueles que já têm acesso privilegiado a bens e serviços, ou seja, àqueles favorecidos economicamente, e que por isso têm acesso garantido às instâncias judiciais superiores (no caso o STF), em detrimento daqueles que, em sentido oposto, não têm acesso aos bens e riquezas sociais, promovendo assim uma verdadeira "sobreposição de iniquidades sociais". Essa é a mesma conclusão do levantamento empírico de Terrazas (2008).

Em sentido contrário, Vianna e Burgos (2002) defendem que a atuação do Judiciário na defesa dos direitos alarga as potencialidades de participação dos cidadãos na agenda pública para além da representação política, fenômeno que os autores vão designar "cidadania complexa". No mesmo sentido o estudo de Wang (2009), que conclui ser o Judiciário uma arena para efetivação de direitos (no caso, à saúde) dos menos favorecidos, mas condiciona sua conclusão à atuação de instituições que sejam capazes de garantir o acesso à justiça dessas populações, o Ministério Público e a Defensoria Pública. No caso dessa última, a potencialidade para efetivar os direitos das populações carentes é maior, tanto por sua finalidade institucional precípua, alcançar a tutela jurisdicional de direitos fundamentais para essas populações, como por parcerias institucionais firmadas entre ela e secretarias de Estado, visando o cumprimento programático desses direitos.

Nesse sentido, a Defensoria Pública pode consistir em um (novo) ator estratégico na cena da judicialização das políticas públicas, 
acrescendo inclusive novos paradigmas de atuação a velhos embates e impasses entre o direito e a política.

Neste artigo propomos apresentar o complexo quadro da atuação judicial em conflitos fundiários urbanos em seu contexto mais atual, levando em consideração a entrada em cena de novos atores -, também aqui a atuação estratégica da Defensoria Pública é elemento central de análise - e de novos direitos em disputa - à recorrente polarização entre o direito individual à propriedade e o direito social à moradia, vem acrescer o direito difuso ao meio ambiente saudável - projetando o presente debate para além de sua armadura mais recorrente, a judicialização das políticas públicas.

\section{Conflito Fundiário Urbano e Remoções Forçadas}

O mundo vive atualmente uma crise de insegurança da posse. Assim afirma Raquel Rolnik (2015), a partir de trabalho realizado ao longo de seis anos como relatora especial das Nações Unidas para o Direito à Moradia Adequada. A concretude dessa afirmação é expressa em dados: de acordo com estimativas do Centre of Housing Rights and Evictions (COHRE) aproximadamente 18 milhões de pessoas foram afetadas por remoções forçadas entre 1998 e 2008 (apud ROLNIK, 2015, p. 149). No centro dessa crise encontram-se dois elementos cruciais, ou ainda, um elemento e seu desdobramento: a concentração da propriedade privada urbana e os conflitos dela decorrentes, para os quais o Estado contribui, significativamente, ao não fazer cumprir o direito humano à moradia às maiorias excluídas. A esses conflitos e às múltiplas violações de direitos que eles encetam podemos atribuir o nome de conflitos fundiários urbanos.

No plano internacional, o tema dos conflitos fundiários urbanos e da violação de direitos que podem acompanhar seus desdobramentos é objeto de normativas das Nações Unidas, expressas 
em documentos como o Comentário Geral no 7 do Comitê de Direitos Econômicos, Sociais e Culturais de 1997 e da Ficha Informativa Sobre Direitos Humanos nํㅡㄹ, Rev. 1, de 2005.

Nesses documentos, a terminologia utilizada para se referir aos possíveis desdobramentos gerados pela insegurança da posse são as chamadas "desocupações forçadas" ou "despejos forçados" (forced evictions), descritos como "o afastamento involuntário de pessoas das suas casas ou terras, imputável, direta ou indiretamente, ao Estado" (ONU, 2005, p. 8).

Para diferentes autores, os conflitos fundiários e sua expressão máxima em remoções devem ser compreendidos em um contexto mais amplo de expansão do capitalismo financeiro e da lógica de competição das chamadas cidades globais. Contexto em que a terra não titulada se torna ainda mais vulnerável às remoções, uma vez que pode ser facilmente mobilizada pelo Estado e atores econômicos com o fim de construção de grandes empreendimentos ditos de interesse público e importantes para aumentar as vantagens competitivas dessas cidades (ROLNIK, 2015; SAGLIO-YATZIMIRSKY; LANDY, 2013).

No Brasil, marcado pela urbanização irregular, a insegurança da posse é expressão inconteste das cidades e está na base dos conflitos fundiários urbanos no país, os quais podem ter como desfecho as remoções forçadas. Por remoções forçadas é possível compreender as ações de retirada forçada de populações que ocupam determinada área (pública ou privada), através de atos do poder público (da Administração Pública, em geral), atendendo, não raro, a interesses econômicos específicos de grupos privados, em detrimento de políticas sociais universais.

Já existe atualmente uma definição formal de conflitos fundiários urbanos que serve de referência para o tratamento político do tema no país, proposta pela Resolução nº 87 de 2009, do Conselho das Cidades, que apresenta tais conflitos como a: 
[...] disputa pela posse ou propriedade de imóvel urbano, bem como impacto de empreendimentos públicos e privados, envolvendo famílias de baixa renda ou grupos sociais vulneráveis que necessitem ou demandem a proteção do Estado na garantia do direito humano à moradia e à cidade (art. $3^{\circ}$, inciso I). (BRASIL, 2010).

Saule Júnior e Di Sarno (2013) propõem uma classificação desses conflitos dividindo-os em conflitos fundiários em sentido amplo e em sentido estrito. Os primeiros podem ser entendidos como constitutivos de parte das cidades brasileiras, e se expressam na lógica excludente do nosso processo de urbanização, que relega à população de baixa renda áreas desvalorizadas pelo mercado imobiliário formal, com precária infraestrutura, muitas vezes áreas de risco ou de ocupação interdita por legislação específica. Tais conflitos, advertem os autores, não se expressam somente na explosão das periferias, mas na disputa de centralidades econômicas das cidades. Ou seja, existe uma dimensão constitutiva das nossas cidades, de sua conformação espacial, que é já conflituosa.

O segundo tipo de conflito fundiário, que nos interessa mais diretamente neste artigo, é aquele entendido no sentido estrito:

[...] há situações de conflito com partes nomináveis, proprietários versus ocupantes, ou Poder Público versus particulares, com instauração de ações judiciais e iminência de remoção. São situações causadas por reintegração de posse ou por realização de grandes obras, empreendimentos ou por mero interesse econômico (SAULE JÚNIOR; DI SARNO, 2013, p. 30).

Do ponto de vista do tratamento jurídico conferido ao tema, os instrumentos (ações possessórias) mantiveram-se os mesmos, inalterados após a CF de 1988 e toda a normativa que a sucedeu, seguindo o modelo e a formatação dos velhos embates regidos pelo direito civil entre propriedade e posse: o despejo e a reintegração/ manutenção de posse. O despejo designa, originalmente, a ação de 
retomada do imóvel pelo proprietário no contexto de uma relação contratual de locação, não abrangendo a totalidade dos conflitos que se deseja mencionar com a noção de remoção forçada. A reintegração de posse, por outro lado, é o dispositivo jurídico processual usado de maneira mais genérica, ainda hoje, para a retirada de famílias, grupos e movimentos sociais em ocupações realizadas em áreas privadas ou públicas. Ou seja, tem sido ela o instrumento jurídico reclamado em ações judiciais para promover a remoção forçada.

Antes de analisar e problematizar, contudo, o papel e a atuação do sistema de justiça e seus possíveis desdobramentos nesses conflitos, é necessário recuperar os marcos legais, a partir da CF de 1988, que contribuíram para redefinir as noções sobre o direito à moradia e seu tratamento político e institucional, agora inserido num campo mais abrangente e complexo que é o das políticas urbanas.

\section{O Direito À Moradia na Política Urbana: o Direito à Cidade}

A Constituição Federal de 1988, ao limitar o direito irrestrito da propriedade ao cumprimento de sua função social, deu o primeiro passo ao reconhecimento do direito à moradia como direito fundamental. Mas a inclusão expressa do direito à moradia no rol dos direitos sociais só viria no ano 2000, com a Emenda Constitucional no 26.

Um ano depois, o Estatuto da Cidade (Lei no 10.527/2001) seria finalmente promulgado, regulamentando os artigos 182 e 183 da CF de 1988, ou seja, os preceitos acerca da política urbana. No que diz respeito ao direito à moradia, o Estatuto da Cidade apresenta diferentes instrumentos a fim de possibilitar sua efetivação, como a regularização fundiária, as zonas especiais de interesse social, o usucapião, a concessão de uso especial para fins de moradia, dentre outros. Do ponto de vista da discussão que aqui nos interessa, o texto traz ainda um preceito fundamental, a saber, a obrigatoriedade 
de que a propriedade cumpra sua função social, isto é, obedeça aos usos devidos, em prol do bem coletivo, especificados em legislação municipal (Plano Diretor). O princípio da função social da propriedade implica que seu uso deve respeitar a coletividade, não se restringindo, pois, a um direito individual. A ideia subjacente é a de que a própria cidade é um bem coletivo e deve cumprir sua função social, a qual o uso da propriedade está submetido.

É possível dizer que o Estatuto da Cidade representou um marco para o tratamento político do tema da moradia no país, criando uma nova grade de inteligibilidade para a questão da habitação, até então tratada de modo isolado e precário na agenda pública, como a experiência do Banco Nacional de Habitação (BNH), desmantelada ainda na década de 80. A inserção do direito à moradia no quadro maior da política urbana fez com que sua compreensão fosse ampliada e qualificada, entendida agora como uma expressão do direito à cidade. Com isso, o direito à moradia passa a implicar não só o simples habitar, mas o direito à mobilidade, ao lazer, à segurança, ao acesso a serviços e equipamentos públicos, em suma, o acesso à cidade como bem coletivo.

Desse modo, a criação do Ministério das Cidades, em 2003, se inseriu nessa perspectiva e apontou à relevância do tratamento das questões urbanas ao permitir a junção, em um só órgão, de políticas até então dispersas e com isso enfraquecidas (ABRÚCIO, 2005). Assim, sob a responsabilidade do Ministério das Cidades estão centralizadas hoje as diretrizes nacionais sobre saneamento ambiental, habitação, transporte e mobilidade urbana, acessibilidade e programas urbanos, organizados em suas respectivas secretarias, possibilitando coerência interna e maior alcance das políticas.

Desde a promulgação do Estatuto da Cidade, e especialmente nos anos mais recentes, o tema dos conflitos fundiários urbanos vem passando por processo de institucionalização crescente, expresso 
em debates e marcos normativos. Um dos marcos importantes foi a edição, pelo Ministério das Cidades, da Portaria no 587/2008, com o objetivo de criar estrutura dentro do ministério para lidar com o tema, agora a cargo da Secretaria Nacional de Programas Urbanos, com apoio da Secretaria Nacional de Habitação. No ano seguinte, a aprovação da Resolução no. 87/2009, do Conselho das Cidades, também representou marco importante ao recomendar ao Ministério das Cidades a instituição da Política Nacional de Prevenção e Mediação de Conflitos Fundiários Urbanos, ou seja, o estabelecimento de uma diretriz nacional para o enfretamento do problema.

Pese os importantes avanços observados na política urbana e seus marcos constitucionais, e na questão da moradia popular, em particular, nos últimos anos, o que se mostra é que o efetivo direito à moradia e à cidade, mais do que uma realidade a ser celebrada, se apresenta atualmente como objeto de disputa política e social no país.

\section{Judicialização dos Conflitos Fundiários}

O reconhecimento formal (constitucional) da função social da propriedade e sua inserção no ordenamento jurídico nacional são acompanhados de dois efeitos: por um lado, apresentam-se tensões entre o direito ligado à propriedade privada e o direito social à moradia. Tem-se, assim, a hipótese mais correntemente descrita até aqui, em que uma família, um grupo ou uma população ocupa uma área, privada ou pública, e sobre ela se instala um litígio sobre o direito à propriedade, entre os proprietários legais e os ocupantes (ou posseiros, na linguagem do direito civil).

De outro lado, na outra ponta do reconhecimento da função social da propriedade e do direito social à moradia, emerge uma outra dimensão de juridificação das relações sociais e, aqui mais especialmente, do que se tem atribuído o nome judicialização da 
política. Tem-se assim a hipótese, bem menos frequente até o momento, é verdade, em que o Estado é acionado, na figura do Poder Executivo e/ ou administração pública, a fim de garantir o cumprimento da política pública urbana, no que diz respeito ao direito à moradia.

É nesses dois contextos, pode-se dizer, que se colocam em disputa os sentidos e significados de conceitos e direitos. E neles o Estado comparece, a um só tempo, como aquele que apresenta e consolida direitos e aquele que, por vezes, instaura ou permite sua violação, através, por exemplo, do uso da força quando do desfecho violento dos conflitos, da condenação ao desabrigo de famílias despejadas etc.

Enquanto o segundo tipo de conflito, aquele em que o Estado é acionado para que cumpra uma política pública e garanta a efetividade de direitos, mantém-se ainda raro na área da habitação ${ }^{4}$, o primeiro conflito, aquele que opõe propriedade (agora constrita pela função social que deve desempenhar) e posse (agora compreendida em um quadro maior como direito à moradia) mantém-se frequente. Nesse sentido, pode-se dizer que a judicialização de tais conflitos não ficou imune às transformações políticas e avanços legais, ocorrendo hoje em um contexto de crescente discussão acadêmica, entre avanços e conservadorismos institucionais.

Um marco muito relevante no tema diz respeito às discussões geradas em torno da aprovação do novo Código de Processo Civil CPC - (Lei 13.105/2015) que ao longo de anos mobilizou movimentos sociais ligados às lutas do direito à cidade e à moradia, com o objetivo de fazerem reconhecer modificações nas regras processuais capazes

4 É de se registrar que as práticas judiciais que têm levado à "judicialização das políticas públicas" têm sido frequentes, a partir dos anos 2000, no campo das políticas de saúde (já mencionadas), e de educação, com destaque para as ações que postulam medicamentos e tratamentos médicos no caso das primeiras e a abertura de vagas em creche, no caso das últimas. 
de garantir um processo judicial apto a acolher e concretizar o direito à moradia.

$\mathrm{O}$ novo CPC estabelece uma série de procedimentos que devem ser considerados no tratamento dos conflitos fundiários judicializados. Assim, avança no entendimento de uma diferenciação entre ações possessórias individuais e coletivas, ao exigir a realização de audiência de mediação antes de qualquer decisão sobre liminares de desocupação, quando essas recaírem sobre ocupação coletiva. Outro avanço importante diz respeito à obrigatoriedade de citação pessoal dos ocupantes nas ações possessórias, superando a condição anterior de citação por edital que possibilitava arbitrariedades como remoções de pessoas sem oportunidade de apresentar defesa (CARVALHO; RODRIGUES, 2015).

O novo CPC traz ainda outro elemento importante, a saber, a exigência da presença do Ministério Público e da Defensoria Pública nas ações, essa última quando houver população em situação de hipossuficiência econômica. Aqui também se destaca a importância do papel exercido pela Defensoria Pública - instituição que, embora prevista na CF de 1988, vem ganhando maior institucionalidade e protagonismo no sistema de justiça apenas a partir dos anos 2000 reconfigurando de modo significativo o quadro da judicialização das políticas sociais. Para além da efetivação da cidadania pela tutela jurisdicional àqueles a quem os direitos sociais não foram garantidos pelo Estado, a atuação desse órgão nos conflitos fundiários pode fortalecer medidas de regularização fundiária, por acordos institucionais firmados entre os atores públicos, como se verá adiante.

A polarização "direito de propriedade" vs. "direito à moradia", no bojo do debate sobre a função social da propriedade, já vem sendo bastante discutida, como mostram os trabalhos citados anteriormente. E os estudos sobre o comportamento do sistema de justiça têm concluído que as decisões majoritariamente ainda arbitram 
os conflitos segundo a prevalência do direito privado sobre o direito público, ou seja, reconhecendo a primazia da propriedade privada sobre o direito social à moradia e à cidade, pese o avanço legislativo e a crescente atuação e órgãos como a Defensoria Pública no sentido de garantir a efetividade de direitos sociais, pela via judicial, aos desfavorecidos socialmente.

Além, contudo, dos dois campos em que a judicialização dos conflitos fundiários se apresenta, propomos agora um deslocamento em relação a eles, indagando sobre qual o campo de ação possível do sistema de justiça quando a questão em disputa não é somente aquela marcada pela desigualdade social e a precariedade de políticas públicas no país, e que opõe, há décadas, propriedade e posse, mas aquela que opõe direito à moradia e direitos difusos. Para discutir essa situação, apresentaremos um estudo de caso realizado a partir de processos de remoção forçada de populações no extremo sul da cidade de São Paulo, promovidos pela gestão municipal à época (administração Gilberto Kassab, 2008-2011), em nome da defesa dos mananciais de abastecimento público da cidade (SILVA, 2011). A metodologia empregada no estudo foi a observação etnográfica e a realização de entrevistas em profundidade com famílias submetidas às ações de remoção, gestores públicos municipais, lideranças locais, organizações da sociedade civil e defensores públicos que atuaram nesses casos.

\section{Um terceiro Elemento em Cena: os Direitos Difusos}

Ao longo dos últimos anos uma das chaves pelas quais os efeitos perversos da urbanização informal vêm sendo discutidos são os impactos que tal urbanização traz para os recursos naturais e o meio ambiente urbanos. Grandes cidades do mundo em desenvolvimento são interrogadas em estudos que discutem os efeitos 
de uma urbanização que se espraia sem planejamento, alcançando áreas de proteção ambiental, parques nacionais, áreas de nascentes de águas de abastecimento público etc., comprometendo-os, e, no limite, comprometendo as próprias condições de desenvolvimento dessas cidades. Aqui se instaura muitas vezes um novo conflito no campo jurídico, a saber: a oposição entre direito à moradia e direitos difusos, quando populações de baixa renda se instalam em áreas ambientalmente protegidas.

Na Região Metropolitana de São Paulo (RMSP), que tomamos como análise, uma das dimensões em que essa questão se dá diz respeito às ameaças que a urbanização informal traz para áreas localizadas junto a mananciais, que são fonte de água para abastecimento público. Nesses casos, alega-se que, no limite, a permanência do processo de ocupação irregular poria em risco a sustentabilidade dos mananciais de abastecimento, atingindo o direito dos milhões de habitantes deles dependentes.

A problemática ganha força na RMSP no final da década de 1970, no contexto de crescimento da importância do debate ambiental contraposto à pressão da urbanização irregular crescente e aos movimentos de moradia, que se organizavam e ganhavam força no contexto de abertura democrática (MARCONDES, 1999). O embate também marcou as polêmicas em torno das modificações na Lei de Proteção aos Mananciais (Lei Estadual no 898 de 1975).

Contudo, o fato é que a lei não foi capaz de impedir que a ocupação urbana continuasse a pressionar essas áreas, que já na década de 1990 se tornaram objeto de programa estadual criado com o objetivo de diminuir os altos índices de poluição que atingiam o reservatório Guarapiranga, um dos principais responsáveis pelo abastecimento da capital paulista. O Programa de Saneamento Ambiental da Bacia da Guarapiranga se desdobrou, em meados dos anos 2000, no chamado Programa Mananciais, de abrangência estendida para os demais 
sistemas produtores da RMSP. É no âmbito desse programa que em 2007 se constitui, no município de São Paulo, o programa municipal Operação Defesa das Águas.

O objetivo da Operação Defesa das Águas era, basicamente, o de frear o processo de ocupação irregular por meio de remoções das chamadas moradias recentes, inicialmente mal definidas, como se verá a seguir. Eis a cena que coloca em embate o direito social à moradia e o direito difuso ao meio ambiente, ao opor a manutenção dos mananciais paulistas, ameaçada com as construções irregulares, ao direito à moradia de milhares de pessoas que, sem condições de habitação regular, ocuparam essas áreas e lá se estabeleceram há décadas sem infraestrutura adequada, alegadamente colocando em risco sua sustentabilidade.

O caso e seu tratamento pelas instâncias públicas é discutido em detalhes ao longo do trabalho de Silva (2011), mas aqui são recuperados de forma sucinta três elementos chave que orientam nossa discussão. São eles: a) o uso de medida administrativa como base das ações de remoção; b) a remoção sem direitos e a criminalização da população em situação irregular de moradia; c) ação da Defensoria Pública como ator capaz de resguardar o acesso aos direitos dessa população.

O início das ações de tal Operação ocorre na primeira gestão do prefeito Gilberto Kassab (2006/2008), ex-DEM, e é marcado pela edição de uma normativa da Prefeitura de São Paulo, a Ordem Interna no 01 de 2007, que estabelece que remoções de ocupações irregulares em áreas de mananciais possam ser feitas prescindindo de ordem judicial, uma vez sendo constatado tratar-se de "ocupações não consolidadas", sem o esclarecimento dos critérios para a dita "consolidação" e sem qualquer previsão de atendimento e encaminhamento aos possíveis desalojados (SÃO PAULO, 2007). Ao sobrepor a prerrogativa da defesa das águas aos direitos fundamentais dos ocupantes da área, na prática 
o programa conduziu à condenação de famílias ao desabrigo sem qualquer mediação, violando direitos humanos e sociais reconhecidos em âmbito nacional e internacional.

Contudo, havia uma questão ainda mais problemática de flagrante inconstitucionalidade e arbítrio fundante dessa ordem administrativa: ela avocava à Administração Pública um ato que é flagrantemente judicial (e assim submetido a todos os princípios do devido processo legal, sobretudo o contraditório): o despejo. Ao avocar à esfera da administração pública um ato jurisdicional, a Municipalidade prescindiu de enfrentar as questões que garantiam a posse ou a propriedade dessas populações: a posse justa e pacífica de mais de um ano, o direito adquirido de usucapião (nas posses de mais de cinco anos), ou a concessão de uso especial pra fins de moradia, que são instrumentos jurídicos de regularização fundiária.

Um dos primeiros bairros atingidos pelas ações do programa municipal, em 2007, foi o Jardim Gaivotas, localizado no distrito do Grajaú, extremo sul da capital paulista, às margens do reservatório da Billings. Expedida ordem de remoção de 97 famílias moradoras do bairro, suas casas foram demolidas, tendo 11 famílias resistido à remoção, permanecendo no local em situação de completo desabrigamento.

Aqui cumpre sublinhar como se evidencia, nesses eventos, a aura de suspeita e condenação condensadas na figura do "invasor". No caso acima descrito, o que justifica a remoção sem garantia prévia de abrigo para os desalojados é a suspeita que se tem em relação a esses. A categoria do "invasor", construída e alimentada inclusive pelos discursos midiáticos em oposição ao "ocupante", como objeto de suspeita e condenação, formal e simbólica, é o que parece orientar as ações empreendidas sobre os moradores, fornecendo o campo de validade pelo qual tais ações se justificam. 
Nesse contexto de vulnerabilidade criada pelo Estado, ao qual estavam expostas inclusive crianças, os moradores, sem saberem a quem recorrer, acionaram o único órgão de referência pública presente no seu cotidiano: o Conselho Tutelar. É somente esse órgão, um híbrido entre o Estado e a sociedade civil, que acionaria então a Defensoria Pública, promovendo a ponte entre essa população vulnerável e seu pouco atingível acesso à justiça.

A Defensoria Pública ingressa então com uma Ação Civil Pública contra a Municipalidade a fim de anular o ato administrativo da remoção, alegando diversas ilegalidades e violações de direitos, a começar pela inviolabilidade de domicílio (sem ordem judicial), se furtando a Administração a enfrentar o debate sobre o processo de consolidação da ocupação e de regularização fundiária por interesse social (alguns moradores estavam no local há mais de cinco anos).

A judicialização da remoção, a partir da entrada da Defensoria Pública no caso foi o que permitiu que os removidos pudessem ter acesso a direitos mínimos inicialmente negados pela sua condição de moradores em situação irregular, a saber, o encaminhamento para abrigo provisório e, posteriormente, a inscrição em programa público de subsídio ao aluguel. É, portanto, na medida em que esse ator (a Defensoria) promove a judicialização desse ato administrativo, com a finalidade cautelar de resguardar direitos severamente atingidos de uma população que não teria como resguardá-los sem o acionamento judicial, que se reconfiguram as posições assimétricas do conflito instaurado.

Aqui, contudo, em diferença aos casos de judicialização do direito à saúde, em que as demandas visam o fornecimento de um remédio ou tratamento, se esgotando, via de regra, com o pedido cautelar, há todo um intercurso processual que desfavorece aqueles que demandam uma decisão de urgência para resguardar direitos ameaçados, quando essa não é atendida. No caso presente, essa 
solução não veio por meio de uma concessão de liminar que poderia, ainda que provisoriamente, suspender a remoção. No entanto, a participação da Defensoria foi estratégica não apenas pela atuação jurisdicional, mas por sua atuação extrajudicial, através de mediações e acordos institucionais com a PMSP que permitiram, nos dizeres do defensor atuante, uma "solução política" através de uma "construção negociada". Essa solução viria através da OI03 de 2008 (SÃO PAULO, 2008) que, embora tenha mantido o foco nas remoções, passou a resguardar alguns direitos das populações nesses locais, como os encaminhamentos a abrigos e a inscrição em programas habitacionais.

Vê-se assim que a atuação de um órgão estatal em defesa daqueles desprovidos de acesso a recursos sociais, ainda que não tenha sucesso pleno no âmbito da tutela jurisdicional, pode constituir um canal de interlocução dessas populações com as instâncias encarregadas de formular e efetivar as políticas públicas. Desse modo, assim como boa parte da literatura, concordamos que a atuação da Defensoria Pública pode contribuir ao maior acesso dessas populações à agenda pública, mas enfatizamos que numa área como a da política habitacional esse resultado se dá menos no âmbito da judicialização e da atuação do poder judiciário propriamente dita, e mais através de estratégias institucionais construídas ad hoc.

Do ponto de vista do desdobramento da ação judicial, após o intercurso de quase dois anos, o desfecho que resultou do enfrentamento, no mérito da remoção, das tensões entre o direito social de moradia dessas famílias e os direitos difusos ao meio ambiente, foi desfavorável às famílias. Após a Defensoria interpor um recurso de apelação junto a Câmara de Direito Público do Tribunal de Justiça de SP, já no ano de 2010, declinou da competência para julgálo, remetendo-o a uma Câmara Especial do Meio Ambiente daquele Tribunal. Essa decisão já revela em si a posição a priori assumida pelo poder judiciário em conflitos que revelam essa natureza de colidência 
de direitos, inclinando-se claramente à prevalência, em abstrato, do direito ao meio ambiente sobre o direito à moradia. Resta avaliar, contudo, se a decisão definitiva terá enfrentado a colidência desses direitos no caso concreto, assumindo o ônus da argumentação, e atentando a critérios como a proporcionalidade, a adequação e a necessidade (SILVA, 2006), prática, contudo, pouco comum em nossa tradição judicial.

O que interessa reter dessa experiência, além da própria descrição de um novo embate que tem se cristalizado no contexto do conflito fundiário com a entrada em cena dos direitos difusos, é uma dimensão estratégica desempenhada não através do controle judicial das políticas públicas propriamente dito, mas a partir de atores que restabelecem posições no campo, posições que são bastante assimétricas. Nesse contexto, o papel que desempenham atores do sistema de justiça, como a Defensoria Pública, não apenas na atividade jurisdicional, mas sobretudo no aspecto político, complexificam os termos dos embates mais recorrentes nesse campo, que se polarizam entre a plena discricionariedade da administração pública e a supremacia do controle judicial, remetendo para uma miríade de questões que o debate sobre a judicialização das políticas públicas não encerra.

\section{REFERÊNCIAS}

ABRÚCIO, Fernando Luiz. A coordenação federativa no Brasil: a experiência do período FHC e os desafios do governo LULA. Revista de Sociologia e Política, Curitiba, n. 24, p. 41-67, jun. 2005.

BRASIL. Ministério Das Cidades. Conselho Das Cidades. Resolução Recomendada no 87 , de 8 de dezembro de 2009. Recomenda ao Ministério das Cidades instituir a Política Nacional de Prevenção e Mediação de Conflitos Fundiários Urbanos. Diário Oficial da União, Brasília, 25 maio 2010, seção 1, n. 98, p. 88.

CARVALHO, Cláudio Oliveira de; RODRIGUES, Raoni. O novo código de processo civil e as ações possessórias: novas perspectivas para os conflitos 
fundiários coletivos? Revista de Direito da Cidade, Rio de Janeiro, v. 7, n. 4, p. 17501770, out. 2015.

FANTI, Fabíola. Políticas de saúde em juízo: um estudo sobre o município de São Paulo. 2009. 106 f. Dissertação (Mestrado em Ciência Política) - Faculdade de Filosofia, Letras e Ciências Humanas, Universidade de São Paulo, São Paulo, 2009.

FERRAZ, Octavio Luiz Motta; VIEIRA, Fabíola Sulpino. Direito à saúde, recursos escassos e equidade: os riscos da interpretação judicial dominante. DADOS, Rio de Janeiro, v. 52, n. 1, p. 223-251, 2009.

MARCONDES, Maria José de Azevedo. Cidade e natureza: proteção dos mananciais e exclusão social. São Paulo: Studio Nobel; EDUSP/FAPESP, 1999.

OLIVEIRA, Vanessa Elias; NORONHA, Lincoln N. T. Judiciary-executive relations in policy making: the case of drug distribution in the State of São Paulo. Brazilian Political Science Review, São Paulo, v. 5, n. 2, p. 11-46, 2011.

ONU - ORGANIZAÇÃO DAS NAÇÕES UNIDAS. Direitos humanos: a desocupação forçada e os direitos humanos. Genebra, 2005. (Ficha Informativa sobre Direitos Humanos, n. 25). Disponível em: <http://www.gddc.pt/direitoshumanos/Ficha_Informativa25.pdf $>$. Acesso em: 4 maio 2016.

ROLNIK, Raquel. Guerra dos lugares: a colonização da terra e da moradia na era das finanças. São Paulo: Boitempo, 2015.

SAGLIO-YATZIMIRSKY, Marie-Caroline; LANDY, Frederick (Ed.). Megacity slums: social exclusion, space and urban policies in Brazil and India. London: Imperial College Press, 2013. v. 1.

SÃO PAULO. Prefeitura Municipal. Ordem Interna 01, de 03 de maio de 2007. Disponível em: <http://www3.Prefeitura.sp.gov.br/cadlem/secretarias/negocios_ juridicos/cadlem/integra.asp?alt=04052007OI000012007PREF>. Acesso em: 14 mar. 2016.

SÃO PAULO. Prefeitura Municipal. Ordem Interna 03, de 08 de julho de 2008. Disponível em: <http://www3.Prefeitura.sp.gov.br/cadlem/secretarias/negocios_ juridicos/cadlem/integra.asp?alt=09072008OI000032008PREF>. Acesso em: 14 mar. 2016.

SAULE JÚNIOR, Nelson; DI SARNO, Daniela Campos Liborio (Coord.). Soluções alternativas para conflitos fundiários urbanos. Brasília: Ministério da Justiça, Secretaria de Reforma do Judiciário, 2013.

SILVA, Eliane Alves. Governar o ingovernável: gestão da irregularidade urbana em áreas de mananciais em São Paulo. 2011. 134 f. Tese (Doutorado em Sociologia) - 
Faculdade de Filosofia, Letras e Ciências Humanas, Universidade de São Paulo, São Paulo, 2011.

SILVA, Virgílio Afonso. O conteúdo essencial dos direitos fundamentais e a eficácia das normas constitucionais. Revista de Direito do Estado, Belém, v. 1, n. 4, p. 23-51, 2006.

TERRAZAS, Fernanda Vargas; SILVA, Luis Virgilio Afonso. O Poder Judiciário como voz institucional dos pobres: o caso das demandas judiciais por medicamentos. 2008. 62 f. Dissertação (Mestrado em Direito) - Faculdade de Direito da Universidade de São Paulo, Universidade de São Paulo, São Paulo. 2008.

TEUBNER, Gunther. The transformation of Law in the welfare state. In: (Ed.) Dilemmas of law in the welfare state. Berlim: Walter de Grutyer, 1986. P3-12.

VIANNA, Luiz Werneck; BURGOS, Marcelo Baumann. Revolução processual e democracia progressiva. In: VIANNA, Luiz Werneck (Org.). A democracia e os três poderes no Brasil. Belo Horizonte: UFMG; Rio de Janeiro: IUPERJ/FAPERJ, 2002. p. $17-42$.

VIANNA, Luiz Werneck; CARVALHO, Maria Alice Rezende; MELO, Manuel Palacios Cunha. A judicialização da política e das relações sociais no Brasil. Rio de Janeiro: Revan, 1999.

WANG, Daniel Wei Liang. Poder Judiciário e políticas públicas de saúde: participação democrática e equidade. Cadernos Gestão Pública e Cidadania, São Paulo, v. 14, n. 54, p. 51-87. 2009. 